\title{
Dificuldades para a Cooperação entre Hotéis Aglomerados Territorialmente: um estudo da hotelaria em Brasília - DF
}

\author{
Difficulties in the Cooperation Among Clustered Hotels: a study about the hotels in \\ Brasilia - DF
}

\section{Las Dificultades en la Cooperación entre Hoteles Agrupados Territorialmente: un estudio sobre los hoteles en Brasilia - DF}

Newton da Silva Miranda Júnior ${ }^{1}$

Helena Araújo Costa ${ }^{2}$

Valmir Emil Hoffmann ${ }^{3}$

\begin{abstract}
Resumo
Identificar ações de cooperação e analisar dificuldades para estabelecê-las entre hotéis aglomerados territorialmente em Brasília, compreendendo variáveis possivelmente associadas, foram os objetivos do presente estudo realizado por meio de pesquisa com gestores de 28 hotéis. Os dados foram analisados mediante estatística descritiva e testes de associação. Os resultados revelam um cenário sem competição desleal entre os hotéis de Brasília, porém composto por ações de cooperação não densas. A ausência de suporte governamental é o principal fator que dificulta o estabelecimento de parcerias entre eles, seguido pela falta de interesse alheio dos demais hotéis da região em cooperar, assim como a falta de tempo para as reuniões com outros empresários. A carência de capital financeiro e o desconhecimento dos benefícios proporcionados pela cooperação estão entre os fatores menos expressivos. Embora haja boa vontade dos gerentes em colaborar com outros e não seja evidenciada competição predatória entre eles, tais fatores não se mostraram suficientes para a existência de ações de cooperação densas. As análises estatísticas não revelaram associação entre as dificuldades elencadas e as variáveis investigadas.
\end{abstract}

Palavras-chave: Relacionamentos Interorganizacionais; Cooperação; Hotelaria; Brasília-DF.

\begin{abstract}
Identify cooperation activities and analyze difficulties to establish them between clusters hotels in Brasilia were the objectives of this study, conducted with managers of 28 hotels. In addition, we sought to understand variables possibly associated with Those Difficulties. The inputs were analyzed using descriptive statistics and association tests. The results reveal a scenario without

\footnotetext{
${ }^{1}$ Mestrando em Economia pela Universidade de Brasília (UnB). Brasília, Brasil. E-mail: newtondasmjr@gmail.com

2 Doutora em Desenvolvimento Sustentável pela Universidade de Brasília (UnB). Professora Adjunta III da Universidade de Brasília (UnB). Brasília, Brasil. E-mail: helenacosta@unb.br

3 Doutor em Administração de Empresas pela Universidad de Zaragoza, Espanha. Professor Titular do Departamento de Administração na Universidade de Brasília e no Programa de Pós-graduação em Administração na Universidade de Brasília. Brasília, Brasil. E-mail: ehoffmann@unb.br
} 
unfair competition between hotels in Brasilia, but not composed of dense cooperation activities. The absence of government support is the main factor that hinders the establishment of partnerships between them, followed by the lack of alien interests of other hotels in the area to cooperate, as well as the lack of time for meetings with other entrepreneurs. The lack of financial capital and the lack of benefits provided by cooperation are among the least expressive factors. Although there is willingness of managers to collaborate with others and is not evidenced predatory competition between them, these factors were not sufficient for the existence of dense cooperation activities. Statistical analysis revealed no association between the listed difficulties and the variables investigated.

Keywords: Interorganizational Relationships; Cooperation; Hospitality; Brasília-DF.

\section{Resumen}

Identificar las actividades de cooperación y analizar las dificultades para establecerlas entre agrupaciones territorialestels en Brasilia fueron los objetivos de este estudio, llevado a cabo con los directores de 28 hoteles. Además, tratamos de entender las variables posiblemente asociadas a esas dificultades. Los datos se analizaron mediante estadística descriptiva y pruebas de asociación. Los resultados revelan un escenario sin la competencia desleal entre los hoteles en Brasilia, pero no componen de actividades de cooperación densos. La falta de apoyo del gobierno es el principal factor que impide el establecimiento de alianzas entre ellos, seguida de la falta de intereses ajenos de otros hoteles en el área de cooperación, así como la falta de tiempo para las reuniones con otros empresarios. La falta de capital financiero y la falta de beneficios proporcionados por la cooperación son algunos de los factores menos expresivos. Aunque no existe voluntad de los gestores de colaborar con los demás y no se evidencia la competencia depredadora entre ellos, estos factores no fueron suficientes para la existencia de actividades de cooperación densos. El análisis estadístico reveló ninguna asociación entre las dificultades enumeradas y las variables investigadas.

Palabras clave: Relaciones interinstitucionales; Cooperación; Hospitalidad; Brasília-DF.

\section{Introdução}

A concepção de cooperação como a união de indivíduos, grupos, organizações formais e informais que compartilham de objetivos particulares e coletivos não é recente (VERSCHOORE FILHO, 2006). Sua notoriedade deu-se a partir da década de 1970 em virtude dos distritos industriais italianos (FERREIRA JÚNIOR; TEIXEIRA, 2007) e continua despertando interesse de muitos estudiosos até os dias atuais (BALESTRIN et al., 2010).

Conceitualmente, a cooperação é entendida como instrumento em que as partes reconhecem que possuem "recursos, expertise e conhecimento" e que trabalhando juntas (CAPORALI; VOLKER, 2004, p. 43) podem obter ganhos mútuos e atingir objetivos afins (VERSCHOORE FILHO, 2006). Os ganhos que a cooperação pode trazer para as empresas são bastante difundidos. De acordo com Britto (2002) e Franco (2007), as práticas de cooperação entre 
empresas podem gerar vantagens econômicas, tais como: racionalização de recursos, aumento dos níveis de produção, aproveitamento de oportunidades de negócios e geração de novas ideias. Não obstante, a cooperação entre empresas pode proporciona-lhes também o compartilhamento de conhecimento; a divisão e redução do ônus de pesquisas tecnológicas; diminuição dos riscos inerentes ao cenário competitivo; desenvolvimento de infraestrutura de suporte; possibilidade de promoção em conjunto de cursos, treinamentos e de consultorias; maior acesso às tecnologias de informação; aumento de barganha em comercializações, culminando em melhores preços e maiores descontos (VERSCHOORE FILHO, 2003; LIMA, 2007; VERSCHOORE FILHO; BALESTRIN et al., 2010).

Esses ganhos acabam gerando vantagens para a própria indústria, pois conforme Borin (2006), a cooperação interorganizacional ainda auxilia a criação de emprego, o sucesso industrial e os processos de aprendizagem e a inovação. Ademais, Borin (2006) argumenta que os benefícios conquistados por organizações que atuam em cooperação dificilmente são alcançados por aquelas que atuam isoladamente. A partir disso, é possível entrever que a cooperação pode contribuir para a criação de vantagens em diferentes níveis: para a empresa entendida em nível micro, para a aglomeração de empresas e para a região como um todo (COSTA, 2005).

Quanto às empresas que operam no segmento do turismo, as ações de cooperação entre elas possibilitam, além dos benefícios já enumerados, a promoção do destino turístico onde elas estão inseridas, assim como o desenvolvimento da economia local (COSTA; SOUTO-MAIOR, 2006). Se de um lado estão as evidências de que as ações de cooperação entre empresas possibilitam benefícios, por outro lado existem os significativos esforços de constituição, coordenação e manutenção que essas ações demandam (WEGNER; PÁDULA, 2012). Assim, a cooperação entre organizações é um esforço entre os envolvidos (FELZENSZTEIN et al., 2009), de sorte que se deve enfatizar o coletivo em detrimento do individual (CARRÃO, 2004), sendo vantajoso praticá-la quando os benefícios sobrepõem os custos de se cooperar (LAGEMANN, 2004).

Apesar de os ganhos advindos da cooperação já terem sido bastante explorados pela literatura (VERSCHOORE FILHO, 2003; BORIN, 2006; LIMA, 2007; VERSCHOORE FILHO; BALESTRIN et al., 2010), também se reconhece a complexidade e a dificuldade de instaurá-la no ambiente empresarial. De modo geral, o sucesso em ações de cooperação é considerado uma exceção e não uma regra (PARK; UNGSON, 2001), a exemplo do número expressivo de iniciativas dessa natureza que não atingem plenamente seus objetivos (PEREIRA et al., 2010). Segundo Banal- 
Estañol et al. (2012), estudos empíricos mostram que as taxas de fracasso em arranjos de cooperação entre empresas são altas, sendo que de $30 \%$ a 50\% das parcerias entre empresas fracassam. Quanto à literatura nacional, nota-se em alguns casos o registro da incipiência ou improviso e até mesmo da falta de cooperação entre negócios, especialmente aqueles ligados ao turismo, a exemplo dos estudos de Franco (2012); Teixeira (2012) e Costa et al. (2012).

\section{Aglomerações Geográficas de Empresas e a Dificuldade de Cooperação}

As aglomerações geográficas de empresas constituem um fenômeno presente em diversas regiões do mundo e são denominadas de diferentes formas, tais como: distritos industriais (MOLINA-MORALES; FERNÁNDEZ, 2004), clusters (PORTER, 1998; FELZENSZTEIN et al., 2009), complexos industriais (SANTOS et al., 2004), arranjos produtivos locais (CAPORALI; VOLKER, 2004), entre outras.

Cabe a Marshall (1982) o crédito por perceber as aglomerações geográficas e seu potencial de vicejar uma indústria. $\mathrm{O}$ autor entendeu que a aglomeração de empresas de um mesmo setor (ou subsetor) levava ao crescimento dessa industria localmente, pela capacidade de atração de novos fornecedores e mesmo de novas empresas. Assim, as empresas aglomeradas territorialmente atingiam simultaneamente especialização e complementaridade. Essas empresas aglomeradas geram economias externas locais que diminuem os custos de produção ao proporcionarem um conjunto de mão-de-obra especializada, acesso fácil aos fornecedores de insumos, serviços especializados e possibilidade de disseminação de novos conhecimentos (SCHMITZ; NADVI, 1999; MOLINA-MORALES; FERNÁNDEZ, 2004).

Em uma definição mais recente, Visser (1999) determinou que a aglomeração geográfica de empresas é um processo de acumulação de atividades econômicas e de experiências comerciais de um determinado subsetor numa certa localidade. Apesar de alguns estudos nacionais como o de Cândido e Abreu (2000) indicarem que há evidências que as aglomerações corroboram para a propensão de ambiente de cooperação entre empresas, Rosa (2004) sustenta que as aglomerações geográficas de empresas não ensejam, necessariamente, interação ou colaboração entre elas.

Se por um lado as economias externas justificam alguns benefícios conquistados por empresas aglomeradas (MOLINA-MORALES; FERNÁNDEZ, 2004), por outro lado elas não parecem suficientes para explicar o desenvolvimento dos próprios aglomerados (SCHMIT; NADVI, 1999). Entre as espécies de concentrações geográficas de empresas estão os distritos industriais. 
A atenção dada a eles, crescente nas duas últimas décadas, deve-se ao êxito obtido pela concentração de atividades semelhantes (MOLINA-MORALES; FERNÁNDEZ, 2004). Segundo Knorringa e Meyer-Stamer (1998), distritos industriais são redes de longo prazo desprovidas de relações hierárquicas entre seus integrantes, os quais são predominantemente de pequeno porte.

Estudos sobre a cooperação interorganizacional tendem a evidenciar os benefícios advindos da parceria entre empresas minimizando em suas análises, por outro lado, as dificuldades para o estabelecimento e para a gerência dessas parcerias, conforme asseveram Park e Ungson (2001) e Wegner et al. (2008). Vários são os fatores que podem incidir como obstáculos às ações de cooperação entre empresas, sendo alguns internos a elas, como, por exemplos: dimensão, antiguidade, estratégia, tecnologia; e outros externos a elas, tais como: setor de atividade, mercado e concorrência (FRANCO, 2007). Além do mais, essas dificuldades podem estar associadas às três fases da cooperação propostas por Franco (2007): formação, implementação e desenvolvimento. Segundo esse autor, na fase de formação, que é quando se selecionam os potenciais parceiros, as oportunidades de colaboração são descobertas e exploradas.

Conquanto, vale ressaltar que nem sempre essas oportunidades são facilmente visualizadas, tendo em vista a dificuldade em se encontrar parceiros capacitados (HANSSEN; NOHRIA, 2004). Neste ponto, é pertinente também se salientar que o histórico e a reputação das empresas podem ser fatores cruciais para a escolha delas como parceiras (COSTA; HOFFMANN, no prelo). Em resumo, a implementação da cooperação é o momento em que as partes estabelecem os objetivos da colaboração, assim como os meios disponíveis para se tornar viáveis os acordos estabelecidos (FRANCO, 2007).

Durante a implementação, conforme assevera Franco (2007), é que, sobremodo, são identificados os fatores críticos para o sucesso da cooperação entre as empresas. Em outras palavras, é nesse momento que podem surgir divergências de interesses que redundam em um obstáculo para a cooperação entre os interessados. Além disso, segundo Verschoore Filho (2003), nessa ocasião os envolvidos podem se deparar com dificuldades relacionadas à divisão das tarefas e dos custos. De mesmo modo, podem perceber que não possuem habilidades para trabalhar em grupo (HANSSEN; NOHRIA, 2004) ou inclusive não disponham de condições para se afastar de tarefas rotineiras de sua empresa para trabalhar pela rede (DOTTO; WITTMANN, 2003). 
Por fim, na fase do desenvolvimento, prevalecem os fatores positivos em relação aos negativos, favorecendo-se estabilidade entre as relações de cooperação das empresas envolvidas (FRANCO, 2007). Todavia, é válido salientar que as parcerias entre empresas não estão imunes a fracassos, os quais podem inclusive surgir em redes já constituídas (WEGNER; PÁDULA, 2012). Assim, cita-se o cenário conflituoso que possa existir entre parceiros quando da divisão dos ganhos obtidos pelo coletivo (VERSCHOORE FILHO, 2003), a necessidade de alguma empresa conduzir o processo e se sentir sobrecarregada ou o receio de fazer muito esforço e não obter os resultados esperados (COSTA; HOFFMANN, no prelo).

Outros autores, a exemplo de Knorringa e Meyer-Stamer (1988), frisam que o comportamento de repúdio à cooperação por parte dos empresários pode ser considerado perfeitamente racional. Segundo Knorringa e Meyer-Stamer (1998), há quatro principais razões que explicam o porquê de empresários agirem de maneira não cooperativa com outros: i) receio de que outras firmas descubram os segredos comerciais do estabelecimento deles; ii) as condições macroeconômicas instáveis; iii) a demanda por tempo para preparar e participar de encontros e iv) questões ligadas à cultura e confiança entre os negócios envolvidos.

Souza e Ferraz (2007) sugerem a aversão e o temor ao risco como possíveis fundamentos para a objeção à cooperação empresarial. A boa vontade dos indivíduos em colaborar um com os outros e a presença de empreendedorismo entre eles (WEGNER, 2005), assim como a existência de ambiente amistoso sem práticas de competição acirrada, parecem não ser condições suficientes para impulsionar o estabelecimento e o sucesso de ações de cooperação empresarial (WEGNER; PÁDULA, 2012). Em contraponto, se a predisposição em cooperar não assegura a existência de parcerias, por outro lado, a falta de comprometimento dentro de uma rede configura-se como empecilho à continuidade dela (DOTTO; WITTMANN, 2003). Quanto ao fator geográfico, tampouco a disposição de empresas de forma aglomerada garante práticas de cooperação entre elas (CURTIS; HOFFMANN, 2009).

São recorrentes as evidências que apontam a presença de um agente externo atuando como incentivador e coordenador de parcerias entre empresas, seja esse agente um ente governamental ou não (RAMÍREZ-RANGEL, 2001; CÂNDIDO, 2002; SOUZA; FERRAZ, 2007; TATSCH, 2010; WEGNER; PÁDULA, 2012; COSTA et al., 2012). Isso leva a crer que a cooperação não é uma relação corriqueira ou que se poderia entender como "espontânea". Ramírez-Rangel (2001) destaca a atuação de instituições da esfera pública na promoção da cooperação interorganizacional. Essas instituições públicas são responsáveis, na maioria dos 
casos, em prestar treinamentos, pesquisas, instruções de marketing e de venda, assim como em incentivar aquisições coletivas entre empresas, a exemplo das ações do SEBRAE e SENAC com empreendimentos do turismo em Alagoas (COSTA et al., 2012).

Além de impulsionar parcerias entre empresas, a atuação dos entes governamentais parece ser fundamental à gestão delas (CÂNDIDO, 2002; TATSCH, 2010), sendo que a falta de suporte governamental pode levar as interações cooperativas ao fracasso (SOUZA; FERRAZ, 2007; WEGNER; PÁDULA, 2012). De modo particular no turismo, a presença do governo como ator em alguns destinos pode ser considerado até mesmo fundamental, em função de seu papel de suporte à atividade e também de agregar das empresas envolvidas (HOFFMANN; CAMPOS, 2013).

Somando-se à atuação de um agente externo, aponta-se a relação custo-benefício como outro importante indicativo de durabilidade ou não das ações de cooperação entre empresas (PEREIRA et al., 2010). Os custos, que não são necessariamente financeiros, podem descompensar os benefícios, quando da existência, por exemplo, de situações indesejadas entre os atores de uma rede de cooperação, a exemplo do comportamento oportunista (PARK; UNGSON, 2001; TÁLAMO; CARVALHO, 2010). Por comportamento oportunista, entendese aquele que degenera a confiança do grupo ao visar ganhos de curto prazo em desfavor daqueles de longo prazo (CURTIS; HOFFMANN, 2009), culminando na geração de desconfianças e descumprimento de acordos (SOUZA; FERRAZ, 2007).

Não obstante, a falta de hábito dos empresários em cooperarem pode também ser lida como uma dificuldade para se estabelecer parcerias (SOUZA; FERRAZ, 2007), o que talvez possa corroborar para a falta de conhecimento deles sobre os benefícios que essas uniões podem proporcionar (CARRÃO, 2004). É possível também se entrever que empresários por não abandonarem o conceito de concorrência, não consigam pensar em termos coletivos, tolhendo, dessa maneira, possíveis parcerias (DOTTO; WITTMANN, 2003).

\section{Metodologia}

A pesquisa foi de caráter descritivo e quantitativo. Para a coleta de dados, aplicou-se questionário em encontros pessoais com os gerentes dos estabelecimentos que aceitaram participar do estudo. O questionário foi desenvolvido tendo como referência os instrumentos de pesquisa elaborados por Costa (2005) e Costa (2009). Antes de aplicado definitivamente, foi 
submetido a uma prova preliminar a fim de detectar possíveis falhas semânticas e de redação na elaboração das perguntas.

Quanto ao universo de pesquisa, elaborou-se uma listagem com base em informações obtidas dos endereços eletrônicos do Ministério do Turismo e da Secretaria de Turismo do Distrito Federal, chegando-se ao universo de 38 estabelecimentos. Destes, o total de questionários válidos somou-se em 28 , alcançando um índice de resposta de $73,7 \%$. Para o tratamento dos dados obtidos, utilizou-se o suporte da estatística descritiva e de medidas de associação quiquadrado com auxílio do software SPSS 20.

Foram utilizadas frequências absolutas para resumir e distribuir os respondentes entre as variáveis: a) localização geográfica, b) porte, c) pertencimento ou não a alguma bandeira, e) tempo de atuação do hotel em Brasília. Para classificar os estabelecimentos estudados quanto ao porte empregou-se o critério do SEBRAE, tendo como exemplos os estudos de Costa (2005) e Teixeira (2012).

Na compilação e tratamento dos dados, utilizou-se o teste qui-quadrado, recomendado para aceitar ou rejeitar hipóteses nulas. Sobre o perfil dos hotéis participantes da pesquisa, metade dos respondentes está em cada setor hoteleiro da cidade (sul e norte). Quanto ao porte dos hotéis, podese notar que a maioria é de pequeno e médio portes. No que concerne aos hotéis de bandeiras, 12 pertencem a alguma delas, ao passo que os demais 16 hotéis atuam de modo independente.

Quanto ao tempo de atuação dos hotéis em Brasília, os estabelecimentos apresentaram média de 24 anos. Combinando essa variável com o fato de o hotel pertencer ou não a alguma rede, os dados coletados revelam que, entre os respondentes, nas duas últimas décadas a quase totalidade de novos estabelecimentos hoteleiros instalados nos SHN e SHS pertence a alguma rede nacional ou internacional de hotéis, seguindo a tendência mundial (GOELDNER et al, 2002). Em números, 13 hotéis atuam na capital federal desde a década de 1990 e, entre eles, 11 hotéis pertencem a alguma bandeira.

\section{Resultados}

\subsection{Caracterizações do cenário competitivo}

Segundo Hocayen-da-Silva e Teixeira (2009), a resistência à formação de redes entre hotéis é explicada, na maioria dos casos, pela competitividade acirrada do mercado local e pela presença de comportamento individualista entre os gestores, os quais pensam apenas nos lucros próprios. 
No que concerne aos hotéis estudados, os dados coletados indicam inexpressivos indícios de competitividade acirrada na região, tampouco a existência de comportamentos individualistas, sob a ótica dos respondentes. Para 78\% deles, existem mais parcerias do que desentendimentos entre o empresariado de Brasília, levando-se a acreditar que os hotéis não se enxergam como concorrentes.

Assim, se por um lado a literatura tradicional aponta a rivalidade como fator limitante para a prática de cooperação entre empresas, por outro lado há evidências, a exemplo do estudo de Wegner e Pádula (2012), de que mesmo a inexistência de rivalidade não assegura o estabelecimento espontâneo e eficiente da cooperação. Com auxílio dos dados da pesquisa, fica aparente que o mercado hoteleiro de Brasília é harmônico, sendo que cada estabelecimento possui seu espaço no cenário competitivo em se tratando de disputa por turistas. Na percepção de $75 \%$ dos respondentes, a concorrência por turistas em Brasília é leal, comparando-se a outros destinos turísticos, tais como Jericoacoara, Parnaíba, Barreirinhas (COSTA, 2009).

De modo geral, os empresários ligados ao setor hoteleiro preferem resolver seus problemas conjuntamente $(54 \%)$, todavia trata-se de um valor não significativo quando comparado ao número de empresários que discordaram da assertiva (43\%), percebendo-se balanceamento nas opiniões. Quanto às diferenças de opiniões entre os empresários, 64\% discordaram que elas são facilmente resolvidas, ao passo que $25 \%$ posicionaram-se de maneira contrária. A princípio pode-se pensar que a dificuldade em se lidar com opiniões divergentes impulsione empresários a não resolver seus problemas em conjunto, a exemplo do que ocorre nos destinos de Jericoacoara e Parnaíba (COSTA, 2009). Contudo, o mesmo não se percebeu no destino Brasília. Apesar de as opiniões divergentes entre os empresários desse destino não se resolverem facilmente, prevalece entre eles a preferência na resolução conjunta de problemas.

A exemplo dos estudos de Doz (1996) e Wegner e Pádula (2012) que tratam, entre outros aspectos, da evolução das intenções e ações de cooperação entre empresas ao longo do tempo, questionou-se ao empresariado hoteleiro brasiliense se, atualmente, os hotéis da região cooperam mais do que no passado, tomando-se como referência a década de 1960, data em que começaram a emergir hotéis na região central da cidade, situação essa que se confunde com a própria construção de Brasília (SANTOS, 2005).

Em contraponto, logo em seguida foi perguntado se as parcerias entre os hotéis de Brasília permanecem com a mesma intensidade que no passado. Partindo de suas percepções, $61 \%$ dos 
gerentes afirmaram que atualmente os hotéis cooperam mais do que no passado, de sorte que para $68 \%$ a intensidade da cooperação realmente não é a mesma. Para análise desses itens, a experiência e o conhecimento dos respondentes foi bastante crucial, percebendo-se que gerentes, sobremaneira aqueles com menor experiência de mercado, abstiveram-se de responder. No geral, $21 \%$ dos respondentes não souberam responder o primeiro item, ao passo que $11 \%$ não souberam responder o segundo.

\subsection{Ações de cooperação}

A cooperação entre hotéis pode oscilar desde práticas simples e efêmeras até práticas duradouras e complexas (HOCAYEN-DA-SILVA; TEIXEIRA, 2009; CERQUEIRA et al., 2010). No que concerne aos hotéis de Brasília, percebeu-se, de modo geral, que as parcerias cooperativas entre eles são incipientes e simplistas, o que talvez possa ser explicado: (1) pelo ambiente amistoso vivenciado por eles, pois, segundo Rovere e Carvalho (2004), as relações de cooperação empresariais dependem do contexto no qual os estabelecimentos desempenham suas atividades; ou (2) por se tratar de um aglomerado em estágio de contatos iniciais com interações não expressivas, a exemplo dos empreendimentos de Pirenópolis (Goiás) abordados no estudo de Thomazine (2012) e das empresas de Santa Cruz do Sul (Rio Grande do Sul) abordadas no estudo de Wegner e Pádula (2012).

Uma prática bastante expressiva, verificada entre os gerentes, é a indicação de outros hotéis da região quando os leitos do estabelecimento onde trabalham estão ocupados integralmente. Afora um hotel, todos os demais vinte e sete afirmaram que praticam essa ação (96\%). A alta frequência alcançada por essa ação entre empresas do ramo turístico é associada à baixa exigência de estruturação e formalização para que ela ocorra, de acordo com Costa e Nascimento (2010). Ainda segundo esses autores, essa ação demonstra coesão do destino, embora alguns empresários não a considerem uma ação praticada com vistas a beneficiar o coletivo (FRANCO, 2012).

Em se tratando de ações mais complexas de cooperação, como a realização de compras conjuntas por intermédio de centrais, os dados sugerem que se trata de uma situação pouco expressiva entre os hotéis de Brasília: 26 hotéis afirmaram nunca fazê-lo. Esses resultados vão ao encontro aos encontrados por Andrigui (2007) em estudo com a destinação turística de Urubici. De acordo com Costa e Nascimento (2010), entre as dificuldades de se realizar compras conjuntas estão as exigências de investimentos partilhados e gestão coordenada. Tais 
dificuldades, segundo Ramírez-Rangel (2001), podem ser minimizadas com o auxílio de entidades governamentais.

Basicamente os relacionamentos dos hotéis de Brasília são constituídos pelas informações que eles trocam entre si, de maneira explícita ou não, no cotidiano ou em reuniões e encontros. Para Visser (1999), esses spillovers de informações, ao lado da redução de custos, são as vantagens de níveis mais básicos de transformação de inputs em outputs em aglomerações de empresas.

\subsection{Dificuldades para a cooperação entre os hotéis de Brasília - DF}

Os dados serão apresentados em blocos conforme a ordem decrescente de expressividade dos itens que o compõem, conforme tabela 1 .

Tabela 1: Dificuldades para a cooperação entre os hotéis estudados

\begin{tabular}{c|c|c|c}
\hline \multirow{2}{*}{$\begin{array}{c}\text { Dificuldades Para a Cooperação Entre os Hotéis } \\
\text { Estudados }\end{array}$} & \multicolumn{3}{|c}{$\begin{array}{c}\text { Quantidade de hotéis } \\
\text { respondentes }\end{array}$} \\
\cline { 2 - 4 } & Sim & Não & $\begin{array}{c}\text { Não } \\
\text { Sabe }\end{array}$ \\
\hline Ausência de suporte de entidades governamentais & 16 & 11 & 1 \\
\hline Falta de tempo para reuniões com outros empresários & 9 & 18 & 1 \\
\hline Falta de interesse dos demais hotéis em cooperar com o meu & 9 & 18 & 1 \\
\hline Proteção dos segredos comerciais & 7 & 20 & 1 \\
\hline Receio de fazer muito esforço e obter poucos resultados & 6 & 21 & 1 \\
\hline Experiências negativas em ações passadas de cooperação & 5 & 21 & 2 \\
\hline Falta de experiência em cooperar com outros hotéis & 4 & 23 & 1 \\
\hline Concorrência local & 3 & 23 & 2 \\
\hline Imagem e reputação negativas & 2 & 25 & 1 \\
\hline Falta de interesse de minha parte em cooperar com outros \\
hotéis & 1 & 26 & 1 \\
\hline Desconhecimento dos benefícios proporcionados pela \\
cooperação & 1 & 26 & 1 \\
\hline Falta de capital financeiro & 1 & 26 & 1 \\
\hline Totais & 64 & &
\end{tabular}

Fonte: dados da pesquisa

Entre as dificuldades para o estabelecimento de cooperação entre os hotéis de Brasília, a ausência de suporte de entidades governamentais foi a mais expressiva, com frequência de $25 \%$ das respostas, sendo apontada por 16 hotéis. Isso sugere que os estabelecimentos hoteleiros necessitam de um agente externo para auxiliá-los a construir parcerias, corroborando assim com Santos (2005). É válido salientar que a importância dada pelas empresas à atuação de atores sociais governamentais para o turismo pode variar de destino para destino turístico, citando-se 
como exemplo o estudo comparativo realizado por Thomazine (2012) com empreendimentos de dois estados brasileiros. Além do mais, decorre majoritariamente da literatura consultada, a exemplo de Cândido (2002) e Tatsch (2010), que os programas governamentais são relevantes às redes de cooperação, seja incentivando o estabelecimento (RAMÍREZ-RANGEL, 2001) ou dando suporte após a constituição delas (WEGNER et al., 2008).

Schibany et al. (2001) fazem uma análise dos problemas práticos possivelmente presentes em redes de empresas e o papel do governo em resolvê-los. De acordo com esses autores, a atuação governamental depende do estágio em que a rede se encontra, podendo o auxílio dado variar desde o despertar de consciência para a possibilidade de redes até a ativação da cooperação propriamente dita. Quanto às instituições que fornecem suporte, sejam elas públicas ou privadas, Molina-Morales e Fernández (2004) destacam os centros de assistência tecnológica, as universidades, os centros de treinamentos vocacionais, os institutos locais de pesquisa, entre outros.

Na sequência, com expressividade entre $14 \%$ e $9 \%$ os respondentes indicaram como entraves à cooperação: a falta de tempo deles para reuniões com outros empresários, a falta de interesse dos demais hotéis em cooperar, a proteção dos segredos comerciais e o receio de se fazer muito esforço e se obter poucos resultados. Parece fundamental para o empresariado hoteleiro dispor de tempo para estabelecer relações sociais a fim de transpor as barreiras impeditivas à cooperação (KNORRINGA; MEYER-STAMER, 1998; STACKE et al., 2012).

Pois, logicamente, se não houver tempo disponível entre eles para estabelecer e manter contatos, tanto menos haverá para acordar ações de cooperação. Segundo Schibany et al. (2001), potenciais parcerias demandam intensos e profundos debates entre os participantes a fim de que sejam criadas confiança e uma base de compartilhamento de conhecimento entre os envolvidos. Além do mais, as interações sociais tornam possíveis as trocas de informações e acesso aos recursos das empresas vizinhas, culminando em potenciais ações coletivas de cooperação entre os estabelecimentos (KNORRINGA; MEYER-STAMER, 1998; MOLINA-MORALES; FERNÁNDEZ, 2003).

Em estudo sobre redes e cooperação na destinação turística de Urubici, no estado de Santa Catarina, Andrighi (2007) constatou que entre o empresariado do turismo daquela região os encontros para tratar de ações de cooperação são freqüentes, o que potencializa possíveis benefícios coletivos. No contexto brasiliense, ainda que seja a segunda dificuldade mais 
expressiva no conjunto dos respondentes, a falta de tempo para encontros com outros empresários não parece ser um problema para a maioria dos gerentes, já que 18 hotéis afirmaram não apresentar essa insuficiência, ao passo que somente 9 hotéis revelaram tal dificuldade (14\%).

Em mesma proporção que a dificuldade anterior, encontra-se a percepção de 9 hotéis de que os demais hotéis não se mostram interessados em cooperar com eles (14\%). Isso remete à ideia de que eles teriam interesse, que não é recíproco por parte de outros estabelecimentos. Neste ponto, é válido citar a constatação feita por Oliveira (2011) em estudo com pousadas aglomeradas territorialmente na região da Serra do Cipó (Minas Gerais) em que se percebeu a presença de um clima de indiferença na aglomeração turística quanto à atuação em favor da coletividade. Os motivos, segundo Oliveira (2011), residiram na ausência de condições e interesse das partes envolvidas, sendo que esse último motivo - ausência de interesse - foi o mais expressivo em estudo realizado por Franco (2012) com albergues no Rio de Janeiro.

A falta de interesse a e falta de tempo podem estar ligadas, uma vez que a falta de tempo está relacionado ao que parece à baixa expectativa sobre os ganhos que a cooperação pode gerar. Ao tratar do tema, Franco (2007) salientou que pode existir uma etapa exploratória da cooperação, onde os atores estão testando seus ganhos, com relação à sua dedicação. Pelo que se percebe essa possibilidade não é levada em conta, já que a expectativa deve ser baixa e não a falta de conhecimento em si.

A proteção dos segredos comerciais tende a incidir como um impeditivo ao estabelecimento da cooperação interorganizacional (KNORRINGA; MEYER-STAMER, 1998). Investigando-se a presença desse fator entre os estabelecimentos de Brasília, verificou-se que 7 hotéis concordaram com essa assertiva, correspondendo a $11 \%$ do total de respostas afirmativas entre todos os itens elencados. O receio de fazer muitos esforços e, em contrapartida, obter poucos resultados (COSTA, 2009; CASTRO et al., 2011), foi considerado como possível resistência ao estabelecimento de parcerias cooperativas. Quando questionados sobre esse assunto, a maioria dos respondentes declarou não ser essa uma dificuldade relevante ao estabelecimento de cooperação deles com outros hotéis, sendo que somente 6 hotéis concordaram com a assertiva apresentada. As respostas para esse item ficaram concentradas em $9 \%$ do total de respostas. 
Com menor expressividade, entre $8 \%$ e $3 \%$, seguem as experiências negativas em ações passadas de cooperação, a falta de experiência em cooperar com outros hotéis, concorrência local e a imagem e reputação negativas. De maneira geral, entre as dificuldades menos citadas, estiveram presentes aquelas ligadas a experiências com a cooperação. São poucos (5 hotéis) que acusam as experiências passadas de insucesso como uma dificuldade e ainda menos aqueles (4 hotéis) que indicam a falta de experiência em cooperar como um entrave. $\mathrm{O}$ fato de a maioria dos gerentes não acusarem essas variáveis como responsáveis pelas dificuldades sentidas por eles para as ações de cooperação poderia levar a duas possíveis interpretações: (i) que existe experiência e predominam aquelas positivas ou (ii) que não há histórico de cooperação densa entre eles, como entre os empreendimentos hoteleiros dos municípios de São Paulo abordados por Andrade e Escrivão Filho (2003).

Analisando ambas as alternativas, a primeira pode ser refutada quando se toma por base a informação fornecida pelos hotéis acerca do histórico da cooperação entre eles. A maior parte dos hotéis entende que a cooperação atual, quando comparada àquela em tempos passados, é mais intensa, o que leva a se pensar em certa tendência ascendente. A segunda fica fortalecida a partir da constatação de que as relações entre os hotéis de Brasília são simplistas. As principais atividades realizadas pelos respondentes consistem em trocar informações e indicar outros hotéis. Trata-se de ações básicas, segundo Visser (1999). A indicação de outros hotéis, além de acontecer anonimamente, trata-se de um costume corriqueiro entre empresas desse ramo. Conquanto, nem sequer é considerada uma atividade voltada ao coletivo pelos próprios atores do turismo (FRANCO, 2012). Assim parece ser coerente se pensar que a possibilidade de existir frustração com essa prática é mínima.

Quando questionados se a concorrência local existente entre os hotéis incidia como uma dificuldade à cooperação entre eles, a exemplo do que ocorre entre os hotéis de Curitiba (TEIXEIRA, 2012), 23 respondentes discordaram, sendo que no conjunto de todas as respostas positivas esse item alcançou somente 5\%, levando-se a duas possíveis interpretações: (1) a concorrência não tem influência direta nas relações de cooperação ou (2) a concorrência entre os hotéis de Brasília é inexpressiva, corroborando, desse modo, com os dados expostos anteriormente, quando da caracterização do cenário competitivo. Em se tratando da primeira assertiva, há controvérsias na literatura quanto à influência da competição entre empresas como fator limitante às ações de cooperação entre elas, a exemplo dos estudos empíricos de Teixeira (2012), Wegner e Pádula (2012), Costa et al. (2012) e Franco (2012). 
A reputação positiva é um atributo facilitador de relacionamentos entre empresas concorrentes (SCHIBANY et al., 2001; CURTIS \& HOFFMANN, 2009). Considerando-se essa informação e utilizando uma abordagem diametralmente oposta foi investigado se a possível imagem negativa incidia como um obstáculo ao estabelecimento de relacionamentos cooperativos. De maneira geral, somente 2 hotéis (3\%) afirmaram apresentar dificuldades ao estabelecimento de cooperação quando percebem aspectos negativos em outro. Todavia, os dados coletados não permitem concluir se há ausência de estabelecimentos com má reputação e imagem negativa na realidade investigada, ou se a percepção de aspectos negativos em um estabelecimento é irrelevante para se estabelecer cooperação com ele, o que, em relação a essa última hipótese, contrariaria os resultados dos estudos de Schibany et al. (2001) e Franco (2012).

Por fim, sem muita representatividade ( $2 \%)$, poucos respondentes apontaram a falta de interesse próprio em cooperar com os demais hotéis, assim como o desconhecimento dos benefícios proporcionados pela cooperação e a falta de capital financeiro como obstáculos à cooperação. Em perspectiva contrária à anterior em que se investigou a análise que o hotel respondente fazia quanto à manifestação dos demais hotéis em cooperar com ele, questionou-se aos respondentes se esse interesse existia por parte deles em cooperar com os demais. Esta contraposição foi feita com o objetivo de identificar possíveis indícios de sentimento de autossuficiência entre os hotéis que, conforme Costa e Hoffmann (no prelo), pode ser um dos motivos que justifique a falta de cooperação entre empresas.

Somente um hotel, o que equivale a $2 \%$ de respostas alcançadas, demonstrou que não possui interesse em cooperar com os demais. Isso levanta a hipótese de que existe propensão à cooperação entre os hotéis de Brasília demonstrada pelo interesse de quase totalidade dos hotéis de se relacionarem entre si. Se por um lado o comportamento individualista e o desinteresse em cooperar podem corroborar para a ausência de parcerias (PARK; UNGSON, 2001; TÁLAMO; CARVALHO, 2010), por outro lado, o desejo de se relacionar com os concorrentes (COSTA et al., 2012) ou até mesmo a presença de interesse em cooperar não parecem suficientes para a geração de parcerias entre empresas.

Quanto ao desconhecimento acerca dos possíveis ganhos ligados à cooperação e traçando paralelo com o estudo de Castro et al. (2011) acerca de uma rede de cooperação na Região Central do Paraná, os autores apontam que houve a necessidade de conscientizar alguns empresários sobre os benefícios advindos da união associativa entre eles, pois a maioria não tinha ciência dessas vantagens. De modo igual, em estudo com albergues de Belo Horizonte, 
Costa et al. (2012) constataram a ausência de conhecimento por parte dos empresários acerca dos benefícios proporcionados pela cooperação interempresarial. Assim, percebe-se, com auxílio dos resultados desses estudos, que há uma situação em que o comportamento de não cooperação entre empresas pode ser motivado pelo desconhecimento das vantagens proporcionadas pelas parcerias.

Por outro lado, pode-se pensar na situação em que os empresários possuem conhecimento das vantagens proporcionadas pela cooperação e, mesmo assim, não cooperam. Conforme asseverado anteriormente, segundo Knorringa e Meyer-Stamer (1998) e Curtis e Hoffmann (2009), a cooperação entre empresas é produto de uma escolha racional delas. Por fim, vale também salientar a situação mais comumente pensada em que empresas conhecem os benefícios da cooperação e, por isso, cooperam, a exemplo dos casos de sucesso de ações de cooperação estabelecidas por grandes empresas abordados no estudo de Paula et al. (2012).

Em síntese, as três possibilidades vislumbradas para essa variável são: (i) não cooperação devido ao desconhecimento dos benefícios; (ii) não cooperação, ainda que haja conhecimento dos benefícios e (iii) cooperação, pois há conhecimento dos benefícios. No contexto de Brasília, 26 hotéis discordaram da assertiva de que a dificuldade para cooperar com outros reside no desconhecimento dos benefícios proporcionados pela cooperação. Com base nisso, infere-se que os respondentes possuem conhecimento dos benefícios, refutando-se assim a primeira possibilidade. Pode-se imaginar que exista, no contexto estudado, uma combinação entre a segunda e a terceira possibilidades, a exemplo do cenário percebido em Campo Grande, no estado do Mato Grosso do Sul, por Silva (2004). Ou seja, os gerentes conhecem os benefícios e estabelecem relações entre si, porém ainda de modo incipiente e simplista, sendo que para algumas atividades há grande expressividade de concordância de parcerias e para outras nenhuma expressividade de concordância.

Em suma, também entre os itens menos expressivos, a falta de capital financeiro foi apontada somente por 1 hotel como um obstáculo para as ações de cooperação com outros. Em geral, entre o conjunto de todas as respostas, esse item alcançou somente $2 \%$, quando havia uma expectativa de ser uma dificuldade recorrente e importante, conforme estudo de Costa et al. (2012). Quanto à investigação, a partir do teste do qui-quadrado, de possíveis associações entre as dificuldades listadas e as variáveis: porte, localização geográfica, tempo de atuação dos hotéis na cidade e pertencimento ou não a alguma bandeira hoteleira, não foram encontrados valores significativos, conforme a tabela 2 . 
Tabela 2: Cruzamentos entre variáveis e os valores do qui-quadrado

\begin{tabular}{|c|c|c|c|c|}
\hline & $\begin{array}{c}\text { Tempo } \\
\text { do } \\
\text { Hotel }\end{array}$ & $\begin{array}{l}\text { Porte do } \\
\text { Hotel }\end{array}$ & $\begin{array}{l}\text { Localizaçã } \\
\text { o } \\
\text { Geográfica }\end{array}$ & $\begin{array}{c}\text { Bandeir } \\
\text { a } \\
\text { Hoteleir } \\
\text { a }\end{array}$ \\
\hline Ausência de suporte de entidades governamentais & $\chi 2=0,792$ & $\chi 2=0,457$ & $\chi 2=0,580$ & $\begin{array}{c}\chi 2=0,44 \\
8\end{array}$ \\
\hline $\begin{array}{c}\text { Falta de tempo para reuniões com outros } \\
\text { empresários }\end{array}$ & $\chi 2=0,498$ & $\chi 2=0,277$ & $\chi 2=0,308$ & $\begin{array}{c}\chi 2=0,11 \\
8\end{array}$ \\
\hline $\begin{array}{l}\text { Falta de interesse dos demais hotéis em cooperar } \\
\text { com o meu }\end{array}$ & $\chi 2=0,131$ & $\chi 2=0,615$ & $\chi 2=0,574$ & $\begin{array}{c}\chi^{2}=0,38 \\
4\end{array}$ \\
\hline Proteção dos segredos comerciais & $\chi^{2}=0,781$ & $\chi 2=0,154$ & $\chi 2=0,511$ & $\begin{array}{c}\chi 2= \\
0,709\end{array}$ \\
\hline $\begin{array}{l}\text { Receio de fazer muito esforço e obter poucos } \\
\text { resultados }\end{array}$ & $\chi 2=0,491$ & $\chi 2=0,772$ & $\chi 2=0,592$ & $\begin{array}{c}\chi^{2}=0,62 \\
2\end{array}$ \\
\hline $\begin{array}{l}\text { Experiências negativas em ações passadas de } \\
\text { cooperação }\end{array}$ & $\chi^{2}=0,129$ & $\chi^{2}=0,430$ & $\chi 2=0,325$ & $\begin{array}{c}\chi 2=0,94 \\
7\end{array}$ \\
\hline $\begin{array}{l}\text { Falta de experiência em cooperar com outros } \\
\text { hotéis }\end{array}$ & $\chi^{2}=0,747$ & $\chi^{2}=0,244$ & $\chi 2=0,360$ & $\begin{array}{c}\chi 2=0,56 \\
0\end{array}$ \\
\hline Concorrência local & $\chi^{2}=0,472$ & $\chi 2=0,566$ & $\chi 2=0,256$ & $\begin{array}{c}\chi 2=0,47 \\
0\end{array}$ \\
\hline Imagem e reputação negativas & $\chi^{2}=0,582$ & $\chi 2=0,111$ & $\chi 2=0,595$ & $\begin{array}{c}\chi 2=0,41 \\
6\end{array}$ \\
\hline $\begin{array}{l}\text { Falta de interesse de minha parte em cooperar } \\
\text { com outros hotéis }\end{array}$ & $\chi^{2}=0,389$ & $\chi^{2}=0,352$ & $\chi 2=0,341$ & $\begin{array}{c}\chi^{2}=0,33 \\
3\end{array}$ \\
\hline $\begin{array}{l}\text { Desconhecimento dos benefícios proporcionados } \\
\text { pela cooperação }\end{array}$ & $\chi^{2}=0,504$ & $\chi^{2}=0,580$ & $\chi^{2}=0,341$ & $\begin{array}{c}\chi 2=0,49 \\
8\end{array}$ \\
\hline Falta de capital financeiro & $\chi^{2}=0,497$ & $\chi^{2}=0,448$ & $\chi 2=0,385$ & $\begin{array}{c}\chi 2=0,53 \\
7\end{array}$ \\
\hline
\end{tabular}

Fonte: pesquisa de campo

Entre todos os testes de qui-quadrado realizados, e apesar de nenhum deles ter se revelado significativo, é válido salientar alguns pontos a fim de compará-los a outros estudos. Quanto à dificuldade de cooperação devido à ausência de suporte de entidades governamentais, havia expectativa de que ao menos o porte revelaria associação estatística, a exemplo do que sugerem os resultados do estudo com os empreendimentos do APL Costa dos Corais (COSTA et al., 2012).

Havia expectativa, também, de que a ausência de tempo para reuniões com outros empresários estivesse relacionada, sobremaneira, às variáveis localização e porte. Acreditava-se que uma possível distância física entre os empreendimentos demandaria tempo de deslocamento. Além 
do que se esperava que houvesse influência do porte do estabelecimento sobre a agenda de seu respectivo gerente.

Segundo Schibany et al. (2001), empresários de pequenas empresas frequentemente estão demasiadamente ocupados para considerar e testar novos modelos de negócios com potenciais parceiros. Quanto à idade e à atuação independente ou em rede, esperava-se a influência de fatores sobre a disponibilidade de tempo dos gerentes, como por exemplo, o modo de gestão e a dificuldade que um gerente que responde por um hotel independente pode sentir. Ou seja, supostamente hotéis que atuam em rede podem enviar um representante que se encarregará de repassar informações aos demais.

É válido salientar, segundo Pereira et al. (2010), que as diferenças de perfis entre empresas, tais como localização, público-alvo e volume de compras é um fator que pode influenciar no interesse em se adotar ações de cooperação com outros estabelecimentos. Outro fator que pode inibir o interesse de uma empresa em propor ou instalar uma rede com outras reside na constatação de Schibany et al. (2001) de que os custos tendem a cair principalmente sobre a organização que atua de maneira mais ativa no processo. Ao investigar se as variáveis do presente estudo estariam correlacionadas à mencionada dificuldade, não foram achadas significâncias expressivas. Ou seja, o fato de empresas estarem situadas em diferentes localidades, possuírem portes e tempo de atuação distintos, assim como o fato de pertencerem ou não a alguma bandeira não está associado ao desinteresse em cooperar, conforme valores do teste do qui-quadrado.

Quanto à falta de associação estatística constatada entre a proteção dos segredos comerciais e a localização dos hotéis parece corroborar com a teoria dos spillovers de informações proposta por Visser (1999). Esperava-se também que o receio de se fazer muitos esforços em troca de poucos resultados revelasse associação estatística significativa, sobremaneira, com o porte dos hotéis e o pertencimento a alguma bandeira. Isto é, pressupunha-se que uma mesma ação realizada por hotéis independentes ou de bandeira e de diferentes portes pudesse ser percebida em diferentes proporções de esforço.

Por envolver a experiência com a cooperação no contexto estudado, acreditou-se que as experiências passadas de cooperação e a falta de experiência em cooperar apresentassem associações significativas com, especialmente, a variável tempo de atuação dos hotéis. Não obstante, esperava-se que o desconhecimento dos benefícios proporcionados pela cooperação 
manifestasse alguma associação considerável com a variável porte, tendo em vista que "os benefícios potenciais de cooperação em rede nem sempre são muito bem conhecidos e internalizados nas pequenas empresas" (SCHIBANY et al., 2001, p. 20). Além do mais, esperava-se também haver associação com a variável localização, assim como se acreditou que hotéis independentes que somente vivem o contexto hoteleiro brasiliense pudessem estar em situação desfavorável em relação aos de bandeira presente em várias localidades e, dessa maneira, com maiores chances de contato com benefícios dessa ação.

O fato de serem hotéis maiores ou menores, independentes ou não, mais velhos ou mais novos, possivelmente mude a disponibilidade que os hotéis têm de recursos financeiros. Todavia, nenhuma destas variáveis os diferencia quando se trata de uma possível dificuldade de dispor de recursos financeiros para a cooperação. Neste caso a expectativa de que as empresas tendem a não cooperação porque que eles não têm capital para financiá-la, não parece ser verdadeira.

\section{Considerações Finais}

O artigo teve como objetivo identificar as dificuldades para as práticas de cooperação entre os hotéis concentrados nas áreas geográficas dos setores hoteleiros norte e sul de Brasília - DF. Os gerentes apontaram a ausência de suporte de entidades governamentais, a falta de tempo para reuniões com outros empresários, assim como a falta de interesse de outros hotéis em cooperar com o deles como os itens mais expressivos. Por outro lado, entre os menos expressivos, portanto com pouca relevância para explicar a falta de densidade da cooperação entre eles, os gerentes apontaram a falta de interesse deles em cooperar com os demais, o desconhecimento dos benefícios proporcionados pela cooperação e a falta de capital financeiro. Em outras palavras, apesar de conhecerem os benefícios proporcionados pelas ações de cooperação e não acusarem a falta de capital financeiro como obstáculo, os participantes atribuíam aos demais a falta de suporte ou de interesse para o estabelecimento de ações de cooperação.

Quanto ao papel de um agente externo, percebe-se que considerável parte da literatura aqui apresentada defende a necessidade da atuação de algum ator social, frequentemente ligado ao governo, que coordene ou incentive as ações de cooperação entre empresas. A presença de um agente externo pode minimizar os custos de coordenação das atividades entre diferentes empresas, além de minimizar comportamentos individualistas e oportunistas, mas também não 
tende a garantir a existência da cooperação. Não obstante, a cooperação entre empresas parece não se dar de modo espontâneo e autônomo entre elas.

Quanto ao auxílio público às ações de cooperação entre empresas, seja estabelecendo os contatos iniciais entre elas, seja dando suporte à gerência da rede já estabelecida, pode-se pensar que a atuação do Estado junto às incipientes relações dos hotéis de Brasília possa ser uma saída para cultivar, promover e amadurecer parcerias entre eles, conforme defendido por Cândido (2002) e a exemplo dos casos citados por Silva e Flôr (2010) e Wegner e Padula (2012) de programas públicos no estado do Rio Grande do Sul que auxiliaram empresas a auferirem bons resultados por intermédio de cooperação entre elas. Também fica claro no trabalho de Hoffmann e Campos (2013) que o governo local pode ter um papel importante no financiamento da atividade e na prestação de serviços de suporte. Contudo, o tipo de turismo que se registra aqui possui baixa competição, e o papel do governo parace mais eficaz quando há competição, como salientaram Hoffmann e Campos (2013).

Para se estabelecer ações de cooperação, as dificuldades, sejam de âmbito interno ou externo às empresas, conforme classificação proposta por Franco (2007), devem ser superadas ou suportadas. Segundo Hocayen-da-Silva e Teixeira (2009), a resistência à formação de redes entre hotéis é explicada, na maioria dos casos, pela competição acirrada do mercado local e pela presença de comportamento individualista entre os gestores, os quais pensam apenas nos lucros próprios. No que concerne aos hotéis estudados, os dados indicaram não haver competição predatória entre eles, tampouco comportamentos excessivamente individualistas na ótica dos respondentes. Isso pode significar que os hotéis se encontram em uma situação de baixa competição, onde cooperar ou qualquer outro esforço em termos de estratégia pode trazer pouco retorno. O que parece claro é que a expectativa sobre os eventuais ganhos em cooperar é baixa, o que significa pouco estímulo até mesmo para se tratar do tema de uma forma mais exploratória, como aponta Franco (2007).

Por fim, este estudo foi limitado pelo fato de não se ter conseguido a participação de todos os meios de hospedagem da cidade. Assim, a ampliação do escopo, em termos de número de respondentes locais e de outros destinos são novas fronteiras a explorar, bem como a complementação qualitativa dos dados. 


\section{Referências}

ANDRADE, J. H.; ESCRIVÃO FILHO, E. Cluster e cooperação entre empresas: uma enquête (survey) com pequenos empreendimentos hoteleiros da região central do Estado de São Paulo.Brasília: UEM/UEL/UNB. $\quad$ v. $1 . \quad$ p. $1: 12, \quad 2003 . \quad$ Disponível em: <http://www.anegepe.org.br/edicoesanteriores/brasilia/[44].pdf.> Acesso em 02 dez. 2011.

ANDRIGUI, F. F. A destinação turística de Urubici - SC a partir da ótica das redes interorganizacionais. 2007. 130 f. Dissertação (Mestrado em Turismo e Hotelaria)-Universidade do Vale do Itajaí, Santa Catarina, 2007. Disponível em: <http://www.siaibib01.univali.br/pdf/Fabiela\%20Fatima\%20Andrighi.pdf. >Acesso em 29 set. 2011.

BALESTRIN, A. et al. O Campo de Estudo sobre Redes de Cooperação Interorganizacional no Brasil. RAC. Revista de Administração Contemporânea, v. 14, p. 458-477, 2010. Disponível em: <http://www.scielo.br/pdf/rac/v14n3/v14n3a05.pdf.> Acesso em 14 set. 2011.

BANAL-ESTAÑOL, A. Sucess and failure in strategic alliances: theory and experimental evidence. Cyprus. Anais eletrônicos...Cyprus: Nicosia, p 1:30, 2012. Disponível em: <http://www.diw.de/documents/vortragsdokumente/220/diw_01.c.496331.de/v_2014_seldeslachts_su ccess_earie.pdf.> Acesso em 15 set. 2011.

BORIN, E. C. P. O Sebrae e os Arranjos Produtivos Locais: o caso de Nova Friburgo/RJ. 2006. 247 f. Tese (Doutorado em Planejamento Urbano e Regional) - Universidade Federal do Rio de Janeiro, Rio de Janeiro, 2006. Disponível em: <http://www.ceap.br/material/MAT23042013210525.pdf.> Acesso em 08 set. 2011.

BRITTO, J. Cooperação interindustrial e redes de empresas. In: KUPFER, D.; HASENCLEVER, L. (Orgs.). Economia Industrial: fundamentos teóricos e práticos no Brasil. Rio de Janeiro: Campus, 2002.

CÂNDIDO, G.; ABREU, A. Aglomerados Industriais de Pequenas e Médias Empresas como Mecanismo para Desenvolvimento Regional. In Revista Eletrônica de Administração, ed. 18, vol. 6, n. 6, 2000. Disponível em: <http://www.read.ea.ufrgs.br/edicoes/pdf/artigo_256.pdf.> Acesso em: 18 jan. 2012.

CÂNDIDO, G. A Formação de Redes Interorganizacionais como Mecanismo para Geração de Vantagem Competitiva e para Promoção do Desenvolvimento Regional: o papel do Estado e das políticas públicas neste cenário. READ - Revista Eletrônica da Administração (UFRGS), Porto Alegre - RS, v. 28, n. 8, p. 32:47, 2002. Disponível em: <www.read.adm.ufrgs.br/edicoes/pdf/artigo_95.pdf. >Acesso em: 12 dez. 2011.

CAPORALI, R.; VOLKER, P. Metodologia de Desenvolvimento de Arranjos Produtivos Locais: projeto PROMOS - SEBRAE - BID versão 2.0. Brasília, Sebrae, 2004. Disponível em: <http://www.fiec.org.br/artigos/competitividade/apl-sebrae/apl-sebrae.pdf.> Acesso em 21 jan. 2012.

CARRÃO, A. M. R. Cooperação entre empresas de pequeno porte em pólos industriais: um estudo comparativo. R.Adm., São Paulo, v.39, n.2, p.186:195, 2004. Disponível em: <http://www.rausp.usp.br/download.asp?file=V3902186.pdf.> Acesso em 20 set. 2011.

CASTRO, M.; et al. Relacionamentos interorganizacionais e resultados: estudo em uma rede de cooperação horizontal da região central do Paraná. RAC Eletrônica, v. 15, p. 1:30, 2011. Disponível em: <http://www.scielo.br/pdf/rac/v15n1/v15n1a03.pdf.> Acesso em 11 nov. 2012.

CERQUEIRA, A. C. et al. Redes de cooperação entre pequenas empresas do setor hoteleiro e a rede turística: um estudo de casos múltiplos em Aracaju, Sergipe. Revista Acadêmica Observatório de Inovação do Turismo. Volume V, n. 1, 2010. Disponível em: <www.spell.org.br/documentos/download/204.> Acesso em 22 set. 2012. 
COSTA, H. A. Análise das relações de rede e do perfil da competitividade turística: estudo comparativo entre São Francisco do Sul e Laguna - SC. 2005. 175 f. Dissertação (Mestrado em Turismo e Hotelaria), Universidade do Vale do Itajaí, Balneário Camboriú, 2005.

COSTA, H. A.; SOUTO-MAIOR, A. Sistemas produtivos locais em turismo: relacionamentos estratégicos e aglomeração territorial como vantagens competitivas. Revista acadêmica Observatório de Inovação do Turismo, v. 1, p. 5, 2006. Disponível em: <http://bibliotecadigital.fgv.br/ojs/index.php/oit/article/viewFile/5608/4329.> Acesso em 13 set. 2011.

COSTA, H. A. Mosaico da sustentabilidade em destinos turísticos: cooperação e conflito de micro e pequenas empresas no roteiro integrado Jericoacoara - Delta do Parnaíba - Lençóis Maranhenses. 2009. 296 f. Tese (Doutorado em Desenvolvimento Sustentável), Universidade de Brasília, Brasília, 2009.

COSTA, H. A.; NASCIMENTO, E. P. Relações de cooperação de micro e pequenas empresas (MPE) do turismo: um estudo em Jericoacoara, Delta do Parnaíba e Lençóis Maranhenses (Brasil). Revista Turismo e Desenvolvimento, v. 13, p. 65:74, 2010. Disponível em: <http://dialnet.unirioja.es/servlet/articulo?codigo=3296878.> Acesso em 15 jan. 2012.

COSTA, H. A. et al. Arranjos Produtivos Locais (APL) no Turismo: estudo sobre a Competitividade e o Desenvolvimento Local na Costa dos Corais AL. Revista acadêmica Observatório de Inovação do Turismo, v. III, p. 1:30, 2012. Disponível em: <http://bibliotecadigital.fgv.br/ojs/index.php/oit/article/viewFile/5806/4518>. Acesso em abr. 2012.

CURTIS, L. F.; HOFFMANN, V. E. Características Determinantes de Redes: um Estudo nos Relacionamentos do Setor Hoteleiro das Destinações Turísticas de Gramado e Canela (Rs). Revista de Negócios, v. 14, n. 1, p. 48:62, 2009. Disponível em:

<http://www. siaibib01.univali.br/pdf/Lali\%20Felker\%20de\%20Curtis.pdf.> Acesso em 12 out. 2011.

DOTTO, D.; WITTMANN, M. As redes de pequenas e médias empresas do vale do Rio Pardo e Taquari do Rio Grande do Sul, Brasil: uma análise de estratégias de cooperação empresarial e desenvolvimento regional. In VII Congreso Internacional del CLAD sobre la Reforma del Estado y de la Administración Pública, v., n., p. 28:31, 2003. Disponível em: <http://www.clad.org.ve/siare/biblo/biblo_a.html.> Acesso em 12 set. 2011.

DOZ, Y. L. The evolution of cooperation in strategic alliances: initial conditions or learning processes? Strategic Management Journal, v. 17, p. 55:83, 1996. Disponível em: <http://www.fearp.usp.br/fava/pdf/pdf188.pdf.> Acesso em 12 dez. 2011.

FELZENSZTEIN, C. et al. Do inter-firm cooperation and social networks change over time in regional clusters? In: 25th IMP-conference in Marseille, France, 2009. Disponível em: <http://www.impgroup.org/uploads/papers/7216.pdf. > Acesso em 12 out. 2011.

FERREIRA JÚNIOR, I.; TEIXEIRA, R. M. Redes de pequenas empresas: a aplicação de uma tipologia em uma rede de supermercados. RAM - Revista de Administração Mackenzie, v.8, n.3, p. 128:152, 2007. Disponível em: <http://www3.mackenzie.br/editora/index.php/RAM/article/viewFile/133/2102.> Acesso em 22 set. 2011.

FRANCO, M. J. B. Tipologia de processos de cooperação empresarial: Uma investigação empírica sobre o caso Português. RAC-Revista de Administração Contemporânea, v. 11, n. 3, p. 149:176, 2007. Disponível em:< http://www.scielo.br/pdf/rac/v11n3/a08v11n3.pdf.> Acesso em 15 set. 2011.

FRANCO, A. F. O. Cooperação entre pequenas empresas do turismo: estudo dos albergues no Rio de Janeiro. 2012. 87 f. Monografia (Especialização em Gestão de Negócios Turísticos) -Universidade de Brasília, Brasília, 2012.

GOELDNER, C. R. et al. Turismo: princípios, práticas e filosofias. 8. ed. Porto Alegre: Bookman, 2002. 
HOCAYEN-DA-SILVA, A. J.; TEIXEIRA, R. M. Análise dos relacionamentos interorganizacionais em empresas do setor hoteleiro de Curitiba/PR: estudo comparativo de casos. Revista Brasileira de Pesquisa em Turismo, Rio de Janeiro, v. 3, n. 2, p. 24:48, 2009. Disponível em: <www.spell.org.br/documentos/download/4675.> Acesso em 12 nov. 2012.

HOFFMANN, V. E.; CAMPOS, L. M. S. Instituições de suporte, serviços e desempenho: um estudo em aglomeração turística de Santa Catarina. Revista de Administração Contemporânea, v. 17, n. 1, p. 18:41, 2013. Disponível em:< http://www.anpad.org.br/admin/pdf/EOR545.pdf.> Acesso em 13 nov. 2012.

KNORRINGA, P.; MEYER-STAMER, J. New dimensions in local enterprise cooperation and development: from clusters to industrial districts. In UNCTAD (org.). New approaches to science and technology co-operation and capacity building. ATAS Bulletin XI). New York, Geneve: United Nations, 1998. Disponível em: <http://www.meyer-stamer.de/1999/atas.pdf>. Acesso em 29 jan. 2012.

LAGEMANN, L. Fatores que influenciam a performance de redes de pequenas e médias empresas, 2004. 133 f. Dissertação (Mestrado em Administração), Universidade Federal do Rio Grande do Sul, Porto Alegre, 2004.

LIMA, P.E.S. Redes interorganizacionais: uma análise das razões de saída das empresas parceiras. 2007. 105 f. Dissertação (Mestrado em Administração) - Programa de Pós-Graduação em Administração, Universidade Federal de Santa Maria, Santa Maria, 2007.

MARSHALL, A. Princípios de economia. São Paulo: Abril Cultural. 1982.

MOLINA-MORALES, F.; FERNÁNDEZ, M. How much difference is there between industrial district firms? A net value creation approach. Research Policy, p. 473:486, 2004. Disponível em: <http://www.sciencedirect.com/science/article/pii/S0048733303001719.> Acesso em 12 fev. 2012.

OLIVEIRA, M. F. A dicotomia entre cooperação e competição em um aglomerado territorial turístico. In: SIMPÓSIO DE EXCELÊNCIA EM GESTÃO E TECNOLOGIA, VIII, 2001. Disponível em: <www.aedb.br/seget/artigos11/28214259.pdf.> Acesso em 12 nov. 2012.

PARK, S.; UNGSON, G. Interfirm rivalry and managerial complexity: a conceptual framework of alliance failure. Organization science, v. 12, n. 1, p. 37:53, jan-feb, 2001. Disponível em: <http://orgsci.journal.informs.org/content/12/1/37.full.pdf+html.> Acesso em 19 jan. 2012.

PAULA, I. A. A. Cooperação empresarial: uma análise em casos de sucesso. In: CONVIBRA ADMINISTRAÇÃO - CONGRESSO VIRTUAL BRASILEIRO DE ADMINISTRAÇÃO, 2012. Disponível em: <http://www.convibra.com.br/upload/paper/2012/32/2012_32_4481.pdf.> Acesso em 02 fev. 2012.

PEREIRA, B. D. et al. Desistência da cooperação e encerramento de redes interorganizacionais: em que momento essas abordagens se encontram? RAI - Revista de Administração e Inovação, v.7, p. 62:83, 2010. Disponível em: $<$ http://redalyc.uaemex.mx/src/inicio/ArtPdfRed.jsp?iCve=97317009005. $>$ Acesso em 25 set. 2011.

PORTER, M. Clusters and the new economics of competition. Harvard Business Review, p. 77:90, 1998.

RAMÍREZ-RANGEL, H. Avaliando o terreno: os fundamentos sociais e institucionais da cooperação da pequena empresa. In: GUIMARÃES, N.; MARTIN, S. Competitividade e Desenvolvimento: atores e instituições locais. São Paulo: Editora SENAC, p. 149:175, 2001.

ROSA, A. V. A. Análise do Arranjo Produtivo Local como Estratégia Competitiva de Pequenas Empresas de Transporte Rodoviário de Cargas: o caso do grupo Oeste Transportes de Osvaldo CruzSP. 168 f. Dissertação (Mestrado em Administração), Pontifícia Universidade Católica do Paraná, Curitiba, 2004.

ROVERE, R. L.; CARVALHO, R. L. Cooperação entre pequenas empresas e desenvolvimento local. III CIPEAL - CONFERÊNCIA INTERNACIONAL DE PESQUISA EM EMPREENDEDORISMO 
NA AMÉRICA LATINA, 2004, Rio de Janeiro. Anais...Rio de Janeiro: PUC-RIO, 2004. Disponível em: <www.icesi.edu.co/ciela/anteriores/Papers/pmed/14.pdf.> Acesso em 23 set. 2012.

SANTOS, G. A. G. et al. Aglomerações, arranjos produtivos locais e vantagens competitivas locacionais. Revista do BNDES, Rio de janeiro, v. 11, n. 22, p. 151:179, 2004. Disponível em: < <http://www.bndes.gov.br/SiteBNDES/export/sites/default/bndes_pt/Galerias/Arquivos/conhecimento /revista/rev2207.pdf >. Acesso em 22 fev. 2012

SANTOS, R. C. X. Perfil do setor hoteleiro do Distrito Federal. Brasília: SEBRAE/DF. 90 p, 2005.

SCHIBANY, A. et al. Interfirm co-operation and networking: concepts, evidence and policy. OECD, France, p. 1:30, 2001. Disponível em: <http://www.oecd.org/science/inno/2100807.pdf.> Acesso em 20 fev. 2012

SCHMITZ, H.; NADVI, K. Clustering and industrialization: introduction. World Development, v. 27, n. $9, \quad$ p. $1503: 1514, \quad 1999 . \quad$ Disponível $\quad$ em: <http://backonline.apswiss.ch/6001/schmitz_and_nadvi_clustering_and_industrializationintroduction.pdf.> Acesso em 19 fev. 2012

SILVA, J. A. S. Turismo, crescimento e desenvolvimento: uma análise urbano-regional baseada em cluster, 2004. 480 f. Tese (Doutorado em Ciências da Comunicação), Universidade de São Paulo, São Paulo, 2004.

SILVA, P.; FLÔR, S. A gestão da energia em redes de cooperação: um estudo de caso da Versare Rede de Hotéis. Revista Hospitalidade, v. VIII, n. 2, dez, 2010. Disponível em: $<$ http://www.revistas.univerciencia.org/turismo/index.php/hospitalidade/article/viewFile/328/396.

$>$ Acesso em 23 fev. 2012.

SOUZA, C. A.; FERRAZ, F. T. Fatores críticos de sucesso no desempenho de um pólo: o caso do APL de indústrias de vestuário de Muriaé - MG. Organização \& Estratégia, v. 3, n. 3, p. 302:320, 2007. Disponível em: <http://www.latec.uff.br/bt/V2007/numero3/PDF/BT073_2007.pdf.> Acesso em 23 fev. 2012.

STACKE, A. R. N. et al. Knowledge transfer among clustered firms: a study of Brazil. Anatolia- An International Journal of Tourism and Hospitality Research, London, p. 1:17, 2012. Disponível em: <http://www.tandfonline.com/doi/pdf/10.1080/13032917.2011.653634.> Acesso em 23 dez. 2012.

TÁlAMO, J. R., CARVALHO, M. Redes de cooperação com foco em inovação: um estudo exploratório. Gestão \& Produção, v.17, n.4, p. 747-760, 2010. Disponível em: <http://www.scielo.br/pdf/gp/v17n4/a09v17n4.pdf.> Acesso em 15 nov. 2011.

TATSCH, M. P. Fatores de competitividade de empresas organizadas em redes de cooperação, 2010. 94 f. Dissertação (Mestrado em Engenharia de Produção), Universidade Federal de Santa Maria, Santa Maria, 2010.

TEIXEIRA, R. M. Redes de Cooperação em turismo: Um estudo nas pequenas empresas hoteleiras de Curitiba. Revista de Turismo y Patrimônio Cultural, v. 10, p. 407:416, 2012. Disponível em: <http://www.obsturpr.ufpr.br/artigos/hotelaria02.pdf.> Acesso em: 15 jan. 2012.

THOMAZINE, J. S. Transferência de conhecimento entre empresas aglomeradas territorialmente e sua relação com a competitividade da destinação turística de Pirenópolis/GO: uma análise comparativa com a destinação turística de Urubici/SC. 200f. Dissertação (Mestrado)-Universidade de Brasília. Brasília, 2012.

VERSCHOORE FILHO, J. R. S. O Programa Redes de Cooperação: uma análise dos instrumentos de administração pública para o desenvolvimento sócio-econômico. VIII Congreso Internacional del CLAD sobre la Reforma del Estado y de la Administración Pública, Panamá, 28:31, 2003. Disponível em:<http://unpan1.un.org/intradoc/groups/public/documents/CLAD/clad0047518.pdf. > Acesso em 20 nov. 2011. 
VERSCHOORE FILHO, J. R. Redes de cooperação interorganizacionais: a identificação de atributos e benefícios para um modelo de gestão, 2006. 253f. Tese (Doutorado em Administração), Universidade Federal do Rio Grande do Sul, Rio Grande do Sul, 2006.

VISSER, E. J. A comparison of clustered and dispersed firms in the small-scale clothing industry of Lima. World Development, vol. 27, n. 9, p. 1553:1570, 1999. Disponível em: <http://xcsc.xoc.uam.mx/apymes/webftp/documentos/biblioteca/A\%20Comparison\%20of\%20Clustere d\%20and\%20Dispersed\%20Firms\%20in\%20the\%20Small-

Scale\%20Clothing\%20Industry\%20of\%20Lima.pdf.> Acesso em 12 dez. 2011.

WEGNER, D. Redes horizontais de empresas no Rio Grande do Sul: Um estudo dos fatores influentes na formação e desenvolvimento, 2005. 170 f. Dissertação (Mestrado em Administração), Universidade Federal de Santa Maria, Rio Grande do Sul, 2005.

WEGNER, D. et al. O último que sair apaga as luzes: motivos para a desistência da cooperação interorganizacional e o encerramento de redes de empresas. In: XI Semead, 2008, São Paulo. Empreendedorismo em Organizações, 2008. Disponível em: <http://www.ead.fea.usp.br/semead/11semead/resultado/trabalhosPDF/179.pdf.> Acessado em 12 nov. 2011.

WEGNER, D.; PADULA, A. D. Quando a cooperação falha: Um estudo de caso sobre o fracasso de uma rede interorganizacional. Revista de Administração Mackenzie, v. 13, p. 145:171, 2012. Disponível em: <http://www.scielo.br/pdf/ram/v13n1/a07v13n1.pdf.> Acesso em 15 nov. 2011.

\section{Recebido em: 21/11/2015}

Aprovado em: 28/01/2016 